Estudios Constitucionales, Año 13, No 1, 2015, pp. 91-122.

ISSN 07180195

Centro de Estudios Constitucionales de Chile Universidad de Talca

"La inexistencia de un criterio constitucional de subsidiariedad en la definición de potestades federativas en Brasil"

Emerson Gabardo

\title{
LA INEXISTENCIA DE UN CRITERIO CONSTITUCIONAL DE SUBSIDIARIEDAD EN LA DEFINICIÓN DE POTESTADES FEDERATIVAS EN BRASIL*
}

\author{
THE ABSENCE OF A CONSTITUCIONAL CRITERION OF SUBSIDIARITY IN THE \\ DEFINITION OF FEDERAL POWERS IN BRAZIL
}

\author{
EMERSON GABARDO** \\ Pontificia Universidad Católica de Paraná \\ Universidad Federal de Paraná (Brasil) \\ e.gab@uol.com.br
}

RESUMEN: El objetivo de esta investigación es proponer la inexistencia de un criterio de subsidiariedad en el sistema constitucional brasileño. Este artículo parte desde un análisis de la situación del municipio en el sistema de distribución de potestades federativas en Brasil, siguiéndose al estudio de la reforma administrativa en Brasil y su intento de utilización del criterio de subsidiariedad para la definición de dichas potestades. La conclusión obtenida es que esta propuesta de reforma no ha sido aceptada en Brasil, y tampoco podría ser. Es decir, la inexistencia de un criterio subsidiario a priori para la definición de las relaciones de potestades entre municipios y las demás entidades federativas en Brasil es una característica que debe ser preservada en el sistema brasileño, diferenciándose, por lo tanto, del sistema europeo.

ABSTRACT: The aim of this investigation is to propose the absence of a subsidiarity criterion in Brazilian constitutional system. The article starts with an analysis of the situation of the municipality in the system of federal powers in Brazil, followed by the study of the administrative reform in Brazil and its intent to use the criterion of subsidiarity in the definition of federal powers. However, the conclusion obtained is that this reform proposal was not accepted in Brazil and never should be. In other words, the lack of a subsidiary criterion for the definition of relationships between the municipality and others Federative level' power is a feature that must be preserved in the Brazilian system, differentiating, therefore, of the European system.

Palabras Clave: Subsidiariedad, Potestades federativas, Municipio; Descentralización; Reforma administrativa.

KEY WORDS: Subsidiarity; Federal powers; Municipality; Decentralization; Administrative reform.

\footnotetext{
* Trabajo recibido el 7 de octubre de 2014 y aprobado el 22 de abril de 2015.

** Profesor del Departamento de Derecho Público de la Universidad Federal de Paraná y Profesor del Programa de Doctorado de la Pontificia Universidad Católica de Paraná (Brasil); Doctor en Derecho del Estado en la Universidad Federal de Paraná. Postdoctorado en Derecho Público Comparado por la Fordham University School of Law (EUA). Miembro Fundador del Centro Didattico Euro-americano sulle Politiche Costituzionali da Università del Salento (Italia). Director Adjunto del Instituto Brasileño de Derecho Administrativo.
} 


\section{LA SITUACIÓN DEL MUNICIPIO EN EL SISTEMA DE DISTRIBUCIÓN DE POTESTADES FEDERATIVAS EN BRASIL}

Desde el estricto punto de vista de la estructuración orgánico-dogmática brasileña, según los términos que establece la Constitución Federal de 1988, es necesario que se comprenda el Estado como una persona jurídica de carácter atípico. Su personalidad jurídica es establecida artificialmente a nivel constitucional, reconociendo la primacía de su naturaleza pública (aunque se admitan excepciones, las personas estatales de derecho privado -lo que no deja de ser algo peculiar-). De todos modos, ser una persona esencialmente de Derecho Público significa decir que su organización y relacionamiento con terceros son regidos por normas de idéntica naturaleza, ya sea en sus relaciones externas (fruto del ejercicio horizontal de la soberanía), sea en el espacio interno (resultado del ejercicio vertical de la soberanía). ${ }^{1}$

Ocurre que la República Federativa de Brasil, pese a que se reconozca su existencia político-jurídica como "persona", no ejerce "personalmente" su personalidad. Por razones de eficiencia administrativa y también debido a un proceso histórico de consolidación del sistema federativo ${ }^{2}$, Brasil se encuentra, en primer lugar, dividido en personas políticas (Unión, Estados, Distrito Federal y Municipios), y luego en personas administrativas (Autarquías, Fundaciones Públicas, Empresas Públicas y Sociedades de Economía Mixta). Todas ellas son capaces de auto-administrarse, aunque las primeras puedan innovar en el sistema jurídico por medio de la elaboración de leyes, y que las segundas no tengan dicha prerrogativa, considerando que estas últimas están vinculadas por el principio de legalidad estricta.

Existen, por lo tanto, diversas formas de descentralización que fueron constituidas históricamente en Brasil (y en América Latina como un todo), sea con un perfil político, sea con naturaleza meramente administrativa. ${ }^{3}$ Además, dicho

\footnotetext{
1 Mayores detalles sobre la cuestión de la subsidiariedad horizontal en Brasil pueden ser obtenidos con la lectura de una obra anterior: GABARDO (2009).

2 Resultado de un largo debate que fue típico de la historia política de Brasil. Sobre el tema, véase: NuNES (1999).

3 Jorge Nef hace la siguiente síntesis del mecanismo típico de los órganos descentralizados en Latinoamérica: "Los órganos descentralizados tienen estatutos aprobados en una legislación especial que les confiere una relativa independencia operacional de naturaleza estatutaria, presupuestaria y de personal en relación con los órganos centrales; en algunos casos, ellos operan según las provisiones del derecho privado.” (...) Sin embargo, en los últimos años, hubo algunos cambios importantes. La descentralización funcional fue
} 
fenómeno es típico del incremento de la complejidad social y de las exigencias ante el Estado que no dejaron de ampliarse a partir de la superación del Estado liberal. Maria Sylvia Zanella di Pietro señala al menos tres maneras fundamentales de ser realizada la transferencia de actividades públicas para los niveles inferiores: (i) por criterio geográfico o territorial; (ii) por servicios o funciones; y (iii) por colaboración. Todas ellas tienen su relevancia en el proceso de identificación del titular de la actividad y del prestatario de servicios públicos. Por un lado concretando un objetivo de especialización y por otro utilizando métodos de gestión privada, el Poder Público desarrolló medios de transferencia de sus actividades, objetivando el alcance de resultados más eficientes. ${ }^{4}$ La concesión y el permiso de servicios públicos son ejemplos útiles de esta realidad (que no es nueva, pero que evoluciona pendularmente, según las opciones político-intervencionistas del Estado).

Preliminarmente, cabe destacar que la existencia de atribuciones específicas previamente delimitadas para la titularidad de potestades federativas no soluciona el problema de la interconexión de áreas. Se observa que la doctrina, desde hace mucho, consagró la diferencia entre las facultades exclusivas (concedidas a un ente, con exclusión de los demás, por lo que son prerrogativas indelegables), privativas (propias de una entidad, aunque sujetas a transferencia y suplemento; siendo, de este modo, delegables), concurrentes (cuyas normas generales compiten a la Unión, siendo posible la complementación mediante normas específicas de los Estados-miembros y del Distrito Federal y normas suplementares de los Municipios) y, por último, las comunes (que pertenecen a todos indistintamente, siendo muy variables de acuerdo con el asunto y situación concretas). ${ }^{5}$ No obstante, en muchas situaciones la estipulación formalconstitucional de potestades poco contribuye para la definición de una adecuada regulación pública de sectores. Principalmente considerando que en Brasil es prácticamente un consenso que las normas federales, estatales y municipales no se encuentran en una situación de jerarquía, bajo pena de ser tenida como

sustituida de manera continua por la privatización, desregulación y recorte de funcionarios". NEF (2010), p. 524.

4 Zanella (2002), pp. 51 y ss.

5 Esta es, al menos, una de posibles clasificaciones. Sin embargo, la falta de una sistemática constitucional respecto del asunto vuelve el tema muy controvertido. Para mayores detalles de dicha clasificación y de otras posibles, véase: Dias (2005). 
inconstitucional. ${ }^{6}$ La potestad en la esfera de los servicios públicos puede ser un ejemplo ilustrativo de dicha realidad.

Según el artículo 21 de la Constitución, cabe a la Unión Federal la realización de los servicios públicos postales y de correos aéreos nacional (inciso X), telecomunicaciones (inciso XI), radiodifusión sonora y de sonidos e imágenes (inciso XII, alinea "a"), instalaciones de energía eléctrica y aprovechamiento energético de los cursos de agua (inciso XII, alinea "b"), navegación aérea, aeroespacial e infraestructura aeroportuaria (inciso XII, alinea "c"), transporte ferroviario y marítimo entre puertos brasileños y fronteras nacionales o que transpongan los límites de los Estados (inciso XII, alinea "d"), transporte vial interestatal e internacional de pasajeros (inciso XII, alinea "e"). La atribución para la prestación de dichos servicios es estipulada numerus clausus, una vez que no pueden ser creadas otras que no aquellas que puedan ser encuadradas en uno de los dispositivos ya mencionados.

A los Estados federados cabe, según el párrafo primero del artículo 25, la prestación de los servicios de gas canalizado y, aún, son a ellos destinados todos los servicios públicos privativos del Estado no reservados a la Unión o a los Municipios. Esto significa que, en Brasil, los Estados tienen una importante potestad de carácter residual en el tema.

Ya a los Municipios, en lo que se refiere a la potestad político-administrativa, son reconocidos por el sistema jurídico brasileño como auténticos entes integrantes de la federación, confiriendo a ellos los servicios denominados genéricamente como de "interés local", muy pronto ejemplificados mediante la previsión específica de los servicios de transporte colectivo (dentro, obviamente, de su jurisdicción territorial).

Tradicionalmente en el Derecho Comparado, el Municipio no forma parte de la Federación, y en la tradición constitucional brasileña anterior a la Constitución de 1988 sucedía lo mismo. ${ }^{7}$ En la Constitución de 1891 la autonomía municipal existía para los asuntos de su "peculiar interés". En la de 1934 había temas de carácter político, financiero-tributario y administrativo (lo que significaba una opción por canales descentralizadores).

Ya en la autoritaria Constitución brasileña de 1937 se regresa al modelo centralizado, típico de un Estado con pretensiones unitarias (aunque se previera

6 Macedo (2005), p. 190.

7 Machado (1995), pp. 621 y ss. 
paradójicamente la existencia jurídica de las regiones). ${ }^{8}$ Según Raul Machado Horta, solamente con la Constitución de 1946 es que hubo un robustecimiento del municipio, incluso debido a la prescripción de transferencias presupuestarias obligatorias, a la limitación de la posibilidad de intervención estatal y a la garantía de su efectiva autonomía política, reiterándose la administración de su "peculiar interés”, especialmente en lo que respecta a los servicios públicos locales. La Constitución de 1967 mantuvo el principio de autonomía local, aunque sin incluir el municipio en la distribución de potestades entre los entes federativos (siendo dicha autonomía limitada en 1969, junto con la de los Estados, en beneficio de la Unión). ${ }^{9}$

El sistema de regionalización y autonomía se ha fortalecido en Brasil a partir de los 90 debido a la Constitución Federal de 1988 y a la política de reforma ocurrida en la misma época. La ideología de fortalecimiento de los gobiernos locales fue dominante en el universo político-jurídico del periodo en diversos países de América Latina, principalmente en Brasil o en Chile. ${ }^{10}$ Como afirma Jorge Nef, en este periodo, "bajo el pretexto de una mayor especificidad, los órganos descentralizados territorialmente (particularmente las municipalidades) aumentaron en cantidad, función e importancia", 11 aunque en algunos casos haya ocurrido un fenómeno paradójico de centralización en la práctica de la gestión administrativa. Según Víctor Bazán, la Argentina es un ejemplo de esto, pues aunque la reforma constitucional de 1994 haya pretendido fortalecer el federalismo argentino en el plan de las normas, hay "un intenso déficit en la aplicación real de las mismas". ${ }^{12}$

El problema es que la identificación de los servicios de interés local no es fácil. La imprecisión de dicho concepto jurídico indeterminado puede generar interpretaciones ambiguas que, al final, además de producir alteraciones de perfil

\footnotetext{
8 El artículo 29 de la Constitución de 1937 disponía que: “Os municípios da mesma região podem agrupar-se para instalação, exploração e administração de serviços públicos comuns. O agrupamento, assim constituído, será dotado de personalidade jurídica limitada a seus fins." A su vez, su párrafo primero establecía para el Estado la potestad para "regular as condições em que tais agrupamentos poderão constituir-se, bem como a forma de sua administração."

9 Machado (1995), pp. 627 - 633.

10 En los 90, Chile ha sufrido reformas que democratizaron los municipios, ampliaron la institucionalización de los gobiernos locales y también sus atribuciones. Nogueira (2008), p. 334.

11 Nef (2010), p. 524. Traducción libre.

12 Y sigue el autor: "En otras palabras, no se ha robustecido el federalismo y, en contrapartida, ha crecido disfuncionalmente el centralismo, con el consecuente quebranto de la calidad democrática e institucional". BAZÁN (2013), p. 80.
} 
tecnológico, socioeconómico e institucional, "los intereses locales y regionales se cruzan y se interrelacionan". 13

Es por dicha razón que Rogério Gesta Leal defiende la idea de que el interés local no surge según determinadas ramas, sino en razón de situaciones concretas. Es decir, aunque reconozca "la existencia de temas que interesan a todo el país, pero que, por tener aspectos que exigen reglamentación propia para determinados territorios, deben ser detallados solamente en dichos territorios y no en toda la extensión del país", el autor hace la observación de que "aspectos del mismo asunto pueden exigir un manejo diferenciado por la Unión, por los Estados y por los Municipios". Lo fundamental, en esta perspectiva, es que no se pierda de vista que cabe esencialmente al ente político más cercano al problema la "formación de instrumentos normativos (como también sus consecuentes acciones públicas), capaces de buscar la concreción de la función social de la ciudad". ${ }^{14}$

Esta idea de interés local de las ciudades (aunque tópicamente considerada) es confrontada con la existencia cada vez más expresiva de las regiones metropolitanas (en la actualidad, cuando el enfoque está en los grandes centros de urbanización donde reside la mayor parte de la población brasileña, es imposible el estudio de los servicios de transporte colectivo urbano, por ejemplo, únicamente por el ángulo intramunicipal). Es de aquí la construcción, desde la Enmienda Constitucional No 848 a la Constitución de 1967, de la idea de intereses que serían comunes (ni generales, ni locales). ${ }^{15}$

Es cierto que los aspectos jurídicos e institucionales de las regiones metropolitanas ya están establecidos por la Constitución de 1988. Dispone su artículo 25, párrafo $3^{\circ}$ que "los Estados podrán, mediante ley complementaria, instituir regiones metropolitanas, aglomeraciones urbanas y microrregiones, constituidas por agrupaciones de Municipios limítrofes, para integrar la organización, la elaboración y la ejecución de funciones públicas de interés común”. De este modo, hay una potestad estatal (y no municipal) para las cuestiones de "interés común"

\footnotetext{
13 Musetti (2003), p. 94. Traducción libre.

14 Gesta (2003), pp. 86 y ss. Traducción libre.

15 Raul Machado Horta recuerda el concepto (aún útil) de servicios de interés común contenido en la motivación del proyecto de enmienda: "dejan de ser exclusivo interés local, por vinculados estar a toda la comunidad metropolitana. Pasan a constituir la composición intermunicipal de aquellas localidades y, por ello, deben ser planeados y ejecutados en conjunto por una administración unificada y autónoma, mantenida por todos los municipios de la región, en la proporción de sus recursos, y si estos fueran insuficientes, deben ser complementados por el Estado, o incluso por la Unión, porque sus beneficios también se extenderán a los gobiernos estatal y federal”. Cf.: MACHADO (1995), p. 647. Traducción libre.
} 
(es decir, de interés metropolitano), que se aglutina a la típica potestad legislativa y de policía administrativa concurrente (prevista en el art. 24 -principalmente en cuestiones ambientales y urbanísticas).

Siendo así, la región metropolitana deberá ser organizada por el Estadomiembro, no obstante deba haber la participación de los municipios, no olvidándose de las normas generales de la Unión (especialmente en el tema urbanístico y relativo al medio ambiente, como ya afirmado). Véase que es posible la intervención del Estado Nacional (y de todos sus entes federativos) cuando él desempeña funciones de agente de promoción del desarrollo (y los servicios públicos en esta línea representan fuertes instrumentos de desarrollo). ${ }^{16}$ En lo restante, es común que las Constituciones de los Estados de la Federación destaquen el carácter plural y conexo de la organización y del funcionamiento de las regiones metropolitanas, disponiéndose expresamente sobre la participación de los municipios y de la sociedad civil, lo que acaba por prestigiar la gestión asociada de los servicios públicos, según lo que dispone el artículo 241 de la Constitución Federal.

\section{LA SUBSIDIARIEDAD EN EL CONTEXTO DEL DESARROLLO EUROPEO}

\section{Y ALGUNAS APROXIMACIONES CON EL CONTEXTO BRASILEÑO}

De la misma manera que el federalismo es un concepto típicamente estadunidense, la idea de subsidiariedad es típicamente europea. Sin embargo, a pesar de la gran importancia del principio de subsidiariedad en Europa, dicha noción no está necesariamente relacionada con la idea de desarrollo. Al revés, la idea de subsidiariedad no se adecua mucho al proceso de desarrollo adoptado en Brasil, que prestigia la actuación de la Unión en el primer plan y de los Estados en el segundo plan, para luego partir para las colectividades más cercanas de los ciudadanos. Más que la subsidiariedad, la "solidaridad" ha sido el elemento que equilibra la báscula. Como ejemplo se puede mencionar el caso español. En los 80 y 90 fueron reducidas en un ritmo muy significativo las desigualdades regionales, principalmente entre las comunidades autónomas. Según los datos señalados por

16 Como ejemplo merecen mención dos artículos constitucionales paradigmáticos sobre el tema. El artículo 174 caput dispone que: "Como agente normativo e regulador da atividade econômica, o Estado exercerá, na forma da lei, as funções de fiscalização, incentivo e planejamento, sendo este determinante para o setor público e indicativo para o setor privado". Ya el artículo 182 establece que: "A política de desenvolvimento urbano, executada pelo Poder Público municipal, conforme diretrizes gerais fixadas em lei tem por objetivo ordenar o pleno desenvolvimento das funçôes sociais da cidade e garantir o bem-estar de seus habitantes". 
Rafael López Pintor, las diferencias de distribución del producto nacional entre las regiones es cada vez menor. Y aunque parte de este logro sea indubitablemente debido al crecimiento endógeno, no se puede ignorar el fuerte impacto de la política de compensación interterritorial realizada tanto a nivel nacional, como por labor de la Unión Europea. ${ }^{17}$ Es cierto que la crisis del inicio de este siglo haya afectado dicha realidad, pero sus pilares teóricos siguen siendo los mismos, es decir, pese a que la crisis y los movimientos separatistas (internos y externos a los países del bloque) sigan existiendo, la Unión Europea continúa intacta.

Resulta interesante observar que, mediante un mecanismo de estrecha colaboración, los fondos para el desarrollo utilizados en la Unión Europea (denominados "fondos estructurales") son eminentemente centralizados. ${ }^{18}$ En 1988 fue instituido un Reglamento de Aplicación de los Fondos, construido no a partir del principio de subsidiariedad, sino a partir del principio de cooperación, que supone la creación de un "triángulo" entre región, Estado y Comunidad. ${ }^{19}$

El propio FEDER (Fondo Europeo de Desarrollo Regional), una primera forma de política regional oficial de la UE, no retrata, aún, una concreta muestra de regionalización. Al revés, está asociado a la expansión comunitaria. Él se basa en el art. 255 del Tratado de Lisboa que posibilita a la estructura supranacional la creación de potestades no expresamente previstas en el tratado, desde que sean para atender a los objetivos de la comunidad.

La adopción de políticas no subsidiarias no significa la desconsideración de la situación concreta de las regiones, sino al contrario, configurando un criterio balizador fundamental de las políticas de desarrollo de la Unión Europea. Lo que ocurre es que el fundamento para la adopción de este modelo no es el principio de subsidiariedad, sino el "principio de cohesión social". ${ }^{20}$ La desigualdad en Europa aún es un factor complejo de influencia en el proceso de integración, razón por la que las políticas desarrollistas son de extremada importancia en un primer momento, teniendo como objetivos: a) buscar la transformación de las regiones con escaso desarrollo o en declive industrial acentuado; b) reducir la ruralidad y sectores de densidad poblacional muy baja; c) controlar la situación de paro de

17 LÓPEZ (1993), p. 26.

18 Fondo Europeo de Desarrollo Regional (FEDER), Fondo Social Europeo (FSE), Fondo Europeo de Orientación y Garantía Agrícola (FEOGA) e Instrumento Financiero de Orientación de la Pesca (IFOP). Representaron alrededor de un tercio del presupuesto de la Unión Europea en los 90. Cf.: STUART (2002).

19 Pires (1994), p. 90.

20 StUart (2002), p. 7. 
larga duración; d) evitar el desempleo asociado a las mutaciones industriales y, finalmente, e) fomentar la adaptación estructural de la agricultura y de la pesca. ${ }^{21}$ Para dicha finalidad, y como consecuencia directa de los Länder alemanes, fue introducido en el Tratado de la Unión Europea el "Comité de Regiones", que es una institución de representación con carácter consultivo, según las diferentes estructuras componentes de la Unión.

La idea de creación de las regiones no consiste en algo ya acabado; fue desarrollada paulatinamente a nivel comunitario, volviéndose en una nueva forma de encuadramiento intermedio para la indicación de desarrollo y planificación. En resumen, en los 70 las regiones no existían expresamente en los tratados; en los 80 hasta los 90 surgen las políticas regionales (principalmente desde una perspectiva territorial y económica); y solamente después es que, con el Tratado de Maastricht, las regiones son integradas institucionalmente a la estructura política comunitaria. ${ }^{22}$ Actualmente, ellas tienen gran importancia. Muchas veces lo que importa no son las fronteras jurídicas, sino las económicas y culturales.

Como no podría dejar de ser, la clara tendencia observada en la actuación del Comité es la de interpretar el principio de subsidiariedad como una cláusula de no intervención en los Poderes Públicos en general "cuando los ciudadanos puedan actuar de manera suficiente y eficaz". Al final, según su concepción, la gradación de potestades con el prestigio de los entes inferiores redundaría en una mayor legitimidad democrática, transparencia y eficacia de las acciones. ${ }^{23}$

En el plan internacional, quizás el nivel institucional con mayor conexión entre el desarrollo y la subsidiariedad son los encuentros promovidos por la ONU. La Agenda 21, un documento-compromiso firmado en Río de Janeiro en 1992 en el marco de la "Conferencia de las Naciones Unidas sobre el Medio Ambiente y el Desarrollo", al lado de establecer un concepto de actividades sostenibles a partir del comprometimiento entre generaciones, estableció tres premisas fundamentales: a) la integración de los conceptos de desarrollo, bienestar social y calidad de vida; b) la exigencia de una mejor distribución de la riqueza tanto entre las generaciones presentes, como también de las futuras; c) la proposición de una concreta utilización racional de recursos naturales. Para la realización de estos supuestos, la idea es dar preferencia a la democracia participativa en el

21 StUart (2002), p. 9.

22 Pires (1994), pp. 83-91.

23 D'Oliveira (2003), p. 252. 
lugar de la representativa, transfiriéndose para el nivel local una buena parte del "protagonismo de la ciudadanía". ${ }^{24}$

La parte tercera del Capítulo 28 del Programa aborda el asunto, estableciendo un plan de acciones locales a favor del desarrollo ambiental. ${ }^{25}$ Se intenta, así, sustituir el "gobierno convencional" por un modelo multinivel y relacional, en el que se amplían las posibilidades de las administraciones locales. En términos generales, la Agenda 21 es bastante sectorizada, no traduciéndose en una concreta regla general de subsidiariedad. Sin embargo, parece claro que su espíritu está en las entrelíneas de todo el documento. Consecuentemente, la estrategia territorial europea para la práctica de la sostenibilidad ambiental debe realizarse desde la escala local. En la Cumbre Mundial del Desarrollo Sostenible de Johannesburgo (Rio + 10), de 2002, el reconocimiento de la subsidiariedad fue más enmarcado al ser reconocidas las regiones como el primero y el mayor nivel de subdivisión política dentro de los Estados individualmente representados en la ONU. ${ }^{26}$

Por otro lado, toda esta promoción del principio tiene poco impacto en Estados ya descentralizados (en lo que se refiere al plan vertical). En Europa, el énfasis conferido a la subsidiariedad en los documentos firmados en estos grandes encuentros internacionales termina reflexionando más sobre una ansiedad autonómica política y económica de las regiones y de los ciudadanos que propiamente sobre un instrumento real de desarrollo ambiental (aunque los reflejos de dicha tendencia acaben resultando en la ampliación de la protección y de la sostenibilidad).

En el plan horizontal, se vuelve difícil verificar una real transferencia de potestades, más allá de la ampliación de la participación consultiva y fiscalizadora. Sin duda, en este ámbito el documento tiene connotación y efectos prioritariamente simbólicos. Pese a que se produjo la ampliación de las menciones expresas a la subsidiariedad en el contexto no sólo brasileño y europeo, sino global, quizás fuera más apropiado pensar en un concepto de "responsabilidad compartida". Dicha propuesta parece haber sido acogida por el Tratado de Ámsterdam, además de estar directamente formulada en el "Quinto Programa de Acción Ambiental de la Unión Europea” de 1993. Francisco Javier Sanz Larruga afirma que se trata de una idea mucho más amplia que la de subsidiariedad, ya que un principio para compartir responsabilidades no establece preferencias apriorísticas, sino "una acción

24 Brunet y Coll (2005), p. 425.

25 ONU (2008).

26 Brunet y Coll (2005), p. 429. 
concertada por parte de todos los actores implicados, que deberán cooperar entre si". El concepto de responsabilidad compartida requiere "no tanto la selección de un determinado nivel en perjuicio de otro, más bien, una intervención mixta de actores e instrumentos en los niveles adecuados". ${ }^{27}$

En lo que respecta al particular universo de los Estados aún en desarrollo, como Brasil, se hace necesario huir de las posiciones ingenuas sobre el tema. A pesar de toda la consagración en el plan del "deber ser", tanto en el plan moral como en el jurídico de derechos conectados al desarrollo, existen relevantes obstáculos fácticos. Esto ocurre pues, aunque no exista una falta de recursos financieros a los Estados como Brasil (principalmente considerándose la economía incrementada de la primera década de este siglo) y además de no haber crisis que se verifique en la producción de una económica a escala mundial, hay una profunda crisis de distribución. En el mundo del inicio del siglo XXI, alrededor de trescientos multimillonarios tienen una renta de igual o más de dos mil millones de individuos (como un tercio de la población mundial). ${ }^{28} \mathrm{Y}$ Brasil es uno de los Estados con un mayor grado de desigualdad entre los polos de la pirámide social.

Dicha coyuntura hace que algunos autores defiendan que el desarrollo sea no más que un mito construido en los siglos XIX y XX, a partir de las ideas evolucionistas que no tendrían reales elementos de fundamentación. La "ideología de la felicidad", típica del desarrollismo, sería una construcción teórica sin condiciones efectivas de concreción. ${ }^{29}$ Sin dejar de considerar esta importante perspectiva crítica, no es posible imaginar otra posición que no sea la de la defensa del "deber ser" consagrado en la dogmática constitucional brasileña, que prescribe un modelo de Estado social a partir de una moralidad que permea, influye y determina la aplicación de dichas normas, cuya finalidad es alterar una realidad que no le es compatible, a partir de todos los niveles de la Federación, sin preferencias.

Sin embargo, una de las tendencias conectadas al proyecto de reforma gerencial-liberal permanentemente en debate en Brasil, es exactamente la valoración de una manera de manejo de la gestión pública que pasó a ser llamada de "gobernanza". Sustituyéndose la expresión común "gobierno" por un eufemismo

27 SANZ (1999), p. 561.

28 Rivero (2002), p. 130.

29 Rivero (2002), p. 125. 
que le pudiera extraer la connotación "autoritaria" que eventualmente podría caracterizarla, se empezó a elaborar toda una teoría alrededor de dicha noción. En Europa, el término obtuvo tanto éxito en la comunidad política y académica que fue instituido en 2001 un documento con título "Governanza Europea: un Libro en Blanco". ${ }^{30}$ El contenido del libro se refiere a problemas típicamente europeos como: la necesidad de una mayor participación y apertura del proceso de decisión europea; la adopción de mejores políticas, regulación y resultados del proceso legislativo comunitario; como también la definición de las atribuciones de las instituciones. Empero, también contempla la meta de diseminar las "nuevas ideas de una buena administración" para el resto del mundo. 31 Tanto es así que uno de sus objetivos es justamente instituir un proyecto de "gobernanza global", traspasándose las barreras de Europa, en un intento de reforzar la eficacia de las instituciones internacionales y extranjeras (tanto públicas como privadas). ${ }^{32}$ En Brasil, la idea de "gobernanza" obtuvo poco impacto en el universo jurídico, siendo más relevante para los administradores y los economistas.

Las ideas inherentes a la gobernanza son recibidas con un cierto entusiasmo, principalmente por los actores relacionados con las entidades públicas no gubernamentales y propiamente privadas (del mercado). Tanto es así que ha surgido incluso un "Instituto Brasileño de Gobernanza Corporativa", cuya finalidad es la de defender postulados que puedan "aumentar el valor de la sociedad, facilitar su acceso al capital y contribuir para su continuidad". 33 Se busca ampliar los medios de interlocución y administración de los juegos de intereses sociales. Según Gustavo Henrique Justino de Oliveira, "uno de los obstáculos en la dirección de las políticas estatales está relacionado al débil desempeño del Gobierno en lo que se refiere a la consecución de metas colectivas". Y la respuesta para dicho problema

30 "Los Libros Blancos publicados por la Comisión son documentos que contienen propuestas de acción comunitaria en dominios específicos. Surgen, algunas veces, en la secuencia de Libros Verdes, cuya finalidad consiste en lanzar un proceso de consulta a nivel europeo. Cuando el Consejo acoge favorablemente al Libro Blanco, este puede originar un programa de acción de la Unión Europea en el dominio en causa. (...) Los Libros Verdes son documentos publicados por la Comisión Europea destinados a promover una reflexión a nivel europeo sobre un tema en específico. Invitan, así, a las partes interesadas (organismos y particulares) a participar en un proceso de consulta y debate, con base en las propuestas que presentaron. Los Libros Verdes pueden, a veces, constituir el punto de partida para desarrollos legislativos que son expuestos en los Libros Blancos". Comissão das Comunidades Europétas (2001).

31 Rodríguez-Arana (2006).

32 Comissāo das Comunidades Europétas (2001).

33 La descripción es de Justino de Oliveira. Cf.: Justino (2008), p. 26. 
pasaría por la ampliación de la participación de la sociedad civil por intermedio de más negociaciones, acuerdos y contratos, lo que prestigiaría la visión de un "Estado mediador" en detrimento del tradicional "Estado impositor". 34

Esto no significa que todas las nuevas formas que pasan a desarrollarse en el momento post-Constitución de 1988 ocurran necesariamente desde dicho paradigma. El propio ambiente burocrático, aún antes de las reformas gerenciales de los 90, ya era fuertemente criticado, y en general con razón. ${ }^{35}$ Ejemplo paradigmático de ello es el "Programa Nacional de Desburocratización" instituido en 1979, cuyo objetivo era "simplificar y dinamizar el funcionamiento de la Administración Federal, reducir la interferencia del Gobierno en la actividad privada y facilitar la atención de los usuarios del servicio público". ${ }^{36}$ La idea de reforma y modernización de la Administración Pública burocrática, por lo tanto, no nació con el gerencialismo típico de los 90, y ni siquiera terminó con él, como si él hubiera realizado una "superación dialéctica" o incluso una "ruptura de paradigma epistemológico". 37

De todos modos, y a pesar de las distintas perspectivas posibles, el hecho es que, en el presente momento, se ha vuelto recurrente, como modelo modernizante, el intento de importación del paradigma europeo, enfocado en la idea general de gobernanza y en la proposición de que la subsidiariedad horizontal y vertical era un a priori necesario. Pues, aunque aparentemente dicha idea pueda ser interesante, cabe subrayar que la realidad europea es muy distinta de la de los países en desarrollo, como Brasil.

Diferentemente de la Unión Europea, el enfoque de la gobernanza y de la subsidiariedad se vuelve esencialmente administrativo (en la prestación de servicios) y no en la participación dentro del proceso político de decisión respecto del ejercicio de la función administrativa. Dicha situación acaba por alterar, para peor, el ya retórico discurso tanto de la gobernanza como el de la subsidiariedad (que es más simbólico que real), una vez que desde el punto de vista ontológico

\footnotetext{
34 Justino (2008), pp. 27-28.

35 No fueron pocos los estudios de la época sobre la cuestión de la necesidad de modernización de la Administración Pública brasileña. Como ejemplo, véase la recopilación de textos sobre el asunto conducidos por el Instituto de Planeamiento Económico y Social en el final de los 70. Cf.: Ramos et al. (1980).

36 Brasil (1982), pp. 1 y ss.

37 En realidad, la historia del reformismo administrativo en Brasil es caracterizada por intentos, ni siempre eficaces, de una mejora estructural y funcional del aparato del Estado. Sobre dichos intentos, merece, destacarse que las investigaciones de Beatriz M. de Sousa Wahrlich. Cf.: M. DE Sousa (1974) y Wahrlich (1984).
} 
no innova en nada (o muy poco) en los métodos tradicionales de democracia del Estado de bienestar. Se trata de un discurso construido fundamentalmente como resultado de la perenne dificultad práctica de los gobiernos de los Estados desarrollados y en desarrollo (aunque por motivos radicalmente diversos) de propiciar la proclamada participación efectiva de los ciudadanos en el ejercicio del poder (principalmente en instancias más alejadas, como es el caso, en Brasil, de la Unión Federal). Esto no significa que el discurso sea inútil, una vez que la carencia de realización práctica de una postura estatal más próxima de los individuos justifica plenamente el énfasis en nuevos intentos de realización democrática.

\section{ReForma ADMINISTRATIVA EN BRASIL Y EL INTENTO (FRUSTRADO) DE UTILIZACIÓN DEL CRITERIO DE SUBSIDIARIEDAD COMO CRITERIO}

\section{DE DEFINICIÓN DE POTESTADES}

En Brasil, así como en diversos otros Estados característicamente interventores, se observó en las dos últimas décadas del siglo XX un proceso de reforma del Estado, con un claro sesgo liberal, flexible y con objetivos desestatizadores, aunque con matices bastantes diferenciadores en cada localidad. La propuesta de que sería interesante la transferencia de actividades tenidas como no exclusivas del Estado para la ejecución directa de la sociedad civil organizada gana fuerza y se vuelve hegemónica, confiriendo legitimidad a las reformas estructurales preconizadas. Las nuevas ideas propugnan por un regreso al pasado, con devolución a los individuos de un papel protagonista de su destino. Según explica Marcelo Figueiredo, "Las reformas económicas brasileñas incluyeron tres transformaciones estructurales que se complementan, aunque no se confunden. Dos de ellas fueron precedidas por enmiendas a la Constitución, mientras que la tercera se hizo mediante la edición de legislación infraconstitucional y la práctica de actos administrativos". Las tres transformaciones destacadas por el autor son: 1. La extinción de determinadas restricciones al capital extranjero; 2 . La flexibilización de los monopolios estatales; y 3. La privatización. ${ }^{38}$

Inicialmente, las reformas tenían como foco prioritario no los servicios sociales, sino los servicios públicos privativos, ${ }^{39}$ (como, por ejemplo, las telecomuni-

\footnotetext{
38 Figueiredo (2008), p. 211.

39 Con relación a dicho raciocinio, se adopta la diferenciación de Carlos Ari Sundfeld entre el servicio público (de titularidad estatal) y el servicio social (sin titularidad estatal). Sobre el asunto véase: SundFELD (2002) y Grau (2002), traducción libre.
} 
caciones, energía y transporte) o, aún más profundos, los que se direccionaban a las actividades económicas en sentido estricto ejercidas directamente por el Estado. En este caso, la actuación del Estado debía ser sustituida por la acción espontánea del mercado. La prioridad de dichas áreas resulta de la viabilidad de privatización con incremento de la participación del capital extranjero en la economía nacional y, principalmente, con posibilidad de elevada recaudación financiera venida desde la venta del patrimonio estatal correlacionado a los servicios (valores estos necesarios a la amortización de la deuda externa). Trascurrida cerca de una década del desarrollo de los programas de desestatización (con el efectivo alcance de las finalidades de privatización respecto de las actividades exclusivas), el Estado pasa a tomar los servicios sociales como una cuestión central para la continuidad de dicho proceso de reforma, volcado al mercado y al individuo. Para tanto, se apoya en distintas ideologías liberales y postmarxistas, como también en una mentalidad popular nítidamente favorable a los cambios modernizadores. Diversos cuestionamientos emergen de este nuevo ideario: ¡el individuo tenía alguna responsabilidad antes del Estado social, para que fuera posible perderla? Si no, ¿qué está siendo "devuelto"? Si tenía, ¿por qué el Estado necesita dedicar tanta energía en la promoción del tercer sector?

Una de las respuestas explicaría que justamente sea una actuación indebida, una vez que el tercer sector debe caminar por sus propios medios, debiendo el Estado cuidar de lo que le es peculiar. Sin embargo, en general, las soluciones son mucho más complejas, exigiendo más que una evaluación científica, sino también una opción ética. El modelo de Estado social hizo su elección al asumir la responsabilidad; asumió la responsabilidad por sus acciones y por sus omisiones (principalmente en el tema de derechos económicos y sociales). ${ }^{40}$

Y, además, realmente la experiencia no parece demostrar que en los Estados donde esto ocurrió más intensamente haya habido ampliación de la apatía o irresponsabilidad social. En este contexto, al contrario de respuestas, surge una nueva duda: con la pretensa restricción orgánica del Estado social, ¿irá el individuo a responsabilizarse? Y más que eso, ¿él tendría condiciones para hacerlo? Y si lo hace, ¿esto realmente promueve la constitución de un verdadero espacio público? ${ }^{41}$

\footnotetext{
40 Wunder (2014), pp. 285-328.

41 Estos argumentos y los cuestionamientos señalados referentes a la responsabilidad del individuo en el Estado social fueron desarrolladas originalmente en trabajo publicado bajo el título "Eficiência e legitimidade do Estado". Cf.: GABARDo (2003), pp. 167 y ss.
} 
Las ideas que fueron implementadas en la última década del siglo XX en Brasil fueron elaboradas por el extinto Ministerio de Administración Federal y Reforma del Estado, por intermedio de la elaboración del Plan Director de Reforma del Aparato del Estado de 1995, ${ }^{42}$ que estableció una estructura organizacional supuestamente "modernizadora" para el país, basada en la delimitación de sectores, en la definición de objetivos, en la elaboración de una estrategia de transición y en la fijación de proyectos específicos. La reforma gerencial anhelada objetivaba una Administración Pública volcada para el "ciudadano-cliente" o "ciudadanousuario", en pro de la mejora de la gobernanza del Estado. Se pretendía, por lo tanto, más que una evolución para la democracia, sino una verdadera reforma en la propia democracia. ${ }^{43}$

En dicho intento, los sectores a ser creados serían cuatro: núcleo estratégico (que corresponde a los Poderes Legislativo y Judicial, a la Fiscalía, además de parte del Poder Ejecutivo relativa a los ministros y sus subordinados directos, los responsables de la formulación de políticas públicas), de actividades exclusivas, de servicios no exclusivos, y de producción de bienes y servicios para el mercado. ${ }^{44}$ El objetivo central del núcleo estratégico es el gerenciamiento de la desburocratización, por medio de la promoción y supervisión del proceso de modernización; el de las actividades exclusivas es sustituir la administración burocrática por la gerencial, a través de la adopción de controles a posteriori (servicios públicos como telecomunicaciones, energía y transporte $)^{45}$; la finalidad principal atribuida a los servicios no exclusivos del Estado es su "publicización" (es decir, desestatización con parte del mantenimiento con financiación pública -escuelas, hospitales, centros de investigación, guarderías, museos). Y, al final, para el sector de producción de bienes para el mercado, el objetivo fundamental es la privatización en sentido estricto (por ejemplo, instituciones financieras).

Las principales orientaciones del nuevo modelo se dividían en tres ejes: a) técnico, a partir del control prioritario de resultados de la actividad administrativa, con inspiración en el modelo australiano; b) económico, mediante el fomento de un control por medio de competición administrativa en los servicios públicos (de

42 El Plan Director de la Reforma del Aparato del Estado fue aprobado por la Cámara de Reforma del Estado en su reunión del 21 de septiembre de 1995, siendo posteriormente sometido y también aprobado por el Presidente de la República.

43 BRESSER (1998), pp. 109-112.

44 Brasil (1995), p. 52.

45 Sobre el complejo sistema de controles propuesto por el gerencialismo, véase: CASTRO (2007). 
inspiración en Nueva Zelanda), además del incremento en la contractualización interna del Estado, en el downsizing (reducción general de las nóminas), en el enpowerment (fortalecimiento de la autonomía de gestión) y en la implantación de programas de reingeniería por cualidad total; c) político, enfocando el control social y la estimulación de la participación de los ciudadanos en el ejercicio de la actuación estatal y paraestatal. 46

La definición de objetivos ocurre justamente en función de la división sectorial, además de la adopción de metas globales, que son la descentralización (basada en el principio de subsidiariedad), el aumento de la efectividad del gobierno en la implantación de políticas públicas (principio de eficiencia) y la imposición de límites a la acción estatal en las funciones que no les son propias (se reservan los servicios tenidos como no exclusivos para la propiedad pública no estatal y la producción de bienes y servicios al mercado para la iniciativa privada). ${ }^{47}$

La estrategia de transición se ubica en tres dimensiones complementarias: la institucional-legal (reforma del sistema jurídico, constitucional e infraconstitucional); la cultural (transición de la cultura burocrática para la gerencial); y la de gestión (modernización de la estructura y de la actividad por medio de la adopción de los nuevos métodos a partir de directrices y objetivos). ${ }^{48}$ Como la modificación de la estructura de gestión es la pieza más importante en la transformación del modelo burocrático por el gerencial, se vuelve necesaria la previsión de una serie de proyectos específicos. Los principales eran: de evaluación estructural (destinado a analizar de forma global la organización del Estado); de creación de agencias autónomas (partiéndose de la transformación de las autarquías y de las fundaciones que ejerzan actividades exclusivas del Estado); y de institución de un programa de publicización, especialmente a través de las organizaciones sociales (que son entidades de derecho privado que obtienen autorización para celebrar contratos de gestión a fin de conquistar el derecho a la financiación pública); ${ }^{49}$ posteriormente, también por las organizaciones de la sociedad civil de interés público y de entes afines (organizaciones de servicio público no estatal). ${ }^{50}$

\footnotetext{
46 BRESSER (1998), p. 115.

47 Brasil (1995), pp. 56 y ss.

48 Brasil (1995), pp. 60 y ss.

49 Dicha descripción se trata de la versión adaptada del resumen del Plan Director elaborado para trabajo publicado bajo el título "Princípio constitucional da eficiência administrativa". Cf.: Gabardo (2002), pp. 56-57.

50 Sobre el asunto, véase: BACELlar Filho (2009), pp. 249 y ss.
} 
Cabe subrayar que este programa, de acuerdo con la sistemática de reforma, no se restringía a una simple alteración de carácter formal-institucional, sino que comprendió, en tesis, a una alteración de la cultura del propio entendimiento respecto de la prestación de servicios en Brasil, es decir, pretende alcanzar de forma "irreversible" la esfera de las mentalidades. ${ }^{51}$

Dentro de los puntos atacados, está la denominada "administración unilateral", que sería una reminiscencia de los "orígenes autoritarios" del Derecho administrativo y, por lo tanto, heredera de un momento arbitrario que no es más compatible con los nuevos tiempos en los que uno de los principales paradigmas es el fortalecimiento de la negociación por vía de acuerdos orientados por un modelo multipolar. En las palabras de Gustavo H. Justino de Oliveira, surge una "nueva contractualización administrativa" (caracterizada por la ampliación de la paridad entre la Administración y el particular). ${ }^{52}$ Contractualización ésta que no se dirige solamente a la relación entre el Poder Público y los sujetos privados, sino que renueva la propia visión respecto del vínculo funcional entre el Estado y sus agentes. 53

Dicho modelo emergente de intervención social, apoyado en la ascensión de la mentalidad postmoderna, se presentó a sí mismo como un salto cualitativo en términos de estructura y gestión, en comparación a la "rigidez obsoleta" del régimen jurídico administrativo característico de la burocracia. ${ }^{54} \mathrm{El}$ modelo burocrático es esencialmente meta-pragmático, propugnando la adopción de la impersonalidad como principio fundamental, por la separación del patrimonio público del privado y por la disociación entre la esfera política y administrativa. El alcance de estos supuestos, se caracteriza por la centralización de las decisiones, por el mantenimiento de la jerarquía y la unidad de comando, además de una cierta rigidez en las rutinas y procedimientos (cuyo control sería extensivo). Por dichos motivos, fue tenido como un "régimen de desconfianza" por Bresser Pereira, que pasó a defender una nueva sistemática, basada en la confianza y en el control a posteriori del resultado. ${ }^{55}$

51 BRESSER (1998), p. 236.

52 Justino (2005), p. 576. Traducción libre.

53 Sobre el tema, véase: PinTo (2005).

54 BRESSER (1998), p. 272.

55 BRESSER (1996), p. 271. Traducción libre. 
En este modelo alternativo, fundado en el principio de subsidiariedad, el Estado pasa a ser un ente responsable prioritariamente de la actuación por medio del fomento y dentro de los límites de razonabilidad y excepcionalidad. Para tanto, debe desregular y conceder incentivos fiscales y desgravaciones. La garantía preconizada debe ser solamente de la "igualdad de oportunidades" entre los individuos. Según Fabricio Motta, es interesante notar un punto específico en dicho proceso de reforma, que es el "reconocimiento de nuevas fuentes estatales y extra-estatales de normatividad". Esto dentro de un contexto de Derecho administrativo, que tiene como rasgo la ampliación del "Estado Regulador" y el protagonismo del Poder Ejecutivo. ${ }^{56}$

La reforma augurada, aunque tuviera como foco el ámbito estructural del Estado (su aparato), también cuenta con la referencia inseparable del campo político. Aboga, como no podría dejar de ser, por la configuración de un nuevo entendimiento respecto de la propia democracia. ${ }^{57}$ Según Cabral de Moncada, la subsidiariedad establece un criterio de preferencia para la democracia directa ante la representativa. ${ }^{58}$ En el mismo sentido, Carlo Marzuoli propone que particularmente la subsidiariedad horizontal altera las estructuras de la democracia, enfocando el rol propio del ciudadano como tal. Se pasa de un modelo de democracia representativa a un modelo de primacía de la libertad y autonomía de la sociedad. 59

Sin embargo, dicha orientación no es pacífica. La dificultad del encuadramiento del criterio de subsidiariedad en la sistemática democrática es grande. En Alemania, este tema ya es tratado desde hace mucho. Para diversos autores germánicos (como R. Herzog en su obra Subsidiaritätsprinzip und Staatsverfassung der Staat), el criterio de subsidiariedad consiste en una alternativa dicotómica al democrático. En la medida en que el reconocimiento del principio de democracia es directo en el sistema constitucional alemán, esta supuesta norma (la subsidiariedad) no sería adoptada, ni siquiera implícitamente (en los términos en los que defiende buena parte de la doctrina). ${ }^{60}$

\footnotetext{
56 Мотта (2007), pp. 51-52.

57 BResSer (1998), p. 236.

58 Cabral (2005), p. 37.

59 Marzuoli (2005), p. 81.

$60 \mathrm{Ha}$ afirmado el pensador alemán: "sería necesario elegir entre una Constitución democrática y una Constitución que respeta el principio de subsidiariedad". Dicha citación y el análisis de la doctrina alemana referente al tema fueron realizadas por: D’Oliveira (2003), p. 83. Traducción libre. Según Vital Moreira, "la
} 
Como propone Alessandra Albanese, aunque los sujetos privados puedan satisfacer los intereses públicos, se plantea siempre un "problema de adecuación”, que no alcanza a ser resuelto únicamente por el criterio de eficiencia. Sólo los entes públicos tienen legitimación democrática cualificada e idónea para la realización de un proyecto de transformación social y de mediación de los conflictos. ${ }^{61}$ Esto quiere decir que los requisitos intrínsecos al principio de subsidiariedad no combinan con aquellos inherentes al principio democrático. Esta tesis es minoritaria, una vez que, en regla, ha prevalecido en Brasil y en Europa posiciones como la de Annalisa Gualdani, para quien el principio de subsidiariedad representa un Leitmotiv que armoniza la relación entre los sujetos públicos y privados a partir de la construcción de una nueva forma de ciudadanía, cuya novedad está justamente en el vuelco de titularidad promovida por el nuevo criterio, que prevé el desarrollo de las actividades de interés general, no teniendo más a la administración pública en el centro del sistema, sino los ciudadanos uti singuli y de forma asociada. ${ }^{62}$

\section{LA INEXISTENCIA DE UN CRITERIO SUBSIDIARIO APRIORÍSTICO}

PARA LA DEFINICIÓN DE LAS RELACIONES DE POTESTADES ENTRE MUNICIPIOS Y

\section{LAS DEMÁS ENTIDADES FEDERATIVAS EN BRASIL}

En países como Brasil, en donde la realización de un nivel satisfactorio de desarrollo aún es una tarea no concluida, la defensa de un Estado social interventor y efectivamente impositivo es una exigencia prioritaria que deriva de la propia Constitución. ${ }^{63}$ Además, la importancia de la Unión Federal como instancia de determinación política y administrativa es, todavía, fundamental. Al contrario de lo que se sostiene, en hipótesis ninguna de hecho conduce a la legitimación de alguna actuación autoritaria, una vez que la Constitución Federal de 1988 es un documento hábil para inhibir el arbitrio y fomentar la participación real, mucho más allá de cualquier libro blanco o verde. Conforme aclara de forma

doctrina alemana se pronuncia en general contra la consagración constitucional del principio de subsidiariedad en la Grundgesetz". Y cita como ejemplos: Ehlers (1984), Hendler (1984), Herzog (1987), E. Klein (1974), Mronz (1973), Scheuner (1954 y 67), Stober (1989 y 93), Thieme (1962). Cf.: Moreira (1997), p. 250. Traducción libre.

61 Albanese (2002), p. 82.

62 Gualdani (2007), p. 216.

63 BerCovici (2014). 
perfecta Daniel Wunder Hachem, los dictámenes constitucionales que regulan el Derecho administrativo brasileño se fijan en la idea de una igualdad material garantizada por el Estado. Además, la Constitución se funda en la promesa de "redistribución por medio de la intervención, lo que se podría llamar de Derecho Administrativo Social". ${ }^{64}$

En estos términos, la actividad administrativa típica del régimen jurídico actualmente vigente implica decisiones unilaterales que se legitimarán en razón de la prevalencia del interés público. Tanto mejor y más legítimo si dicha decisión fuera precedida por un amplio debate y participación de los interesados, y seguida de un efectivo control popular, más que el control judicial. No obstante, no se debe olvidar que al día de hoy aún es la democracia representativa la principal forma de realización del interés público y cualquier forma de su restricción es tendencialmente arbitraria, aunque encuentre suelo fértil para su actual diseminación.

Margarida Salema d'Oliveira Martins, fuerte defensora de la subsidiariedad, lista como condiciones para la intervención subsidiaria la incapacidad, la negligencia y la necesidad. Elementos pragmáticos que pueden ser relevados en conjunto o aisladamente y que, en su presencia, compondrían un indicativo interventor. ${ }^{65}$ La gran pregunta que surge a partir de esta conclusión de la autora es: si los ciudadanos quisieran atribuir constitucional o legalmente una función al Estado, no porque son incapaces de realizarla, tampoco porque fueran negligentes en su consecución, ¿ellos podrían hacerlo por el simple hecho de ser conveniente u oportuno? ¿Sería posible que los ciudadanos optaran democráticamente por la intervención del Estado en alguna esfera de la vida social aunque reconociesen la no imprescindibilidad de la actuación del Poder Público?

De acuerdo con el principio de subsidiariedad, la respuesta a dichas preguntas sería negativa, es decir, dicha posibilidad está vedada. En los términos del principio democrático, la respuesta sería afirmativa, es decir, no habría ninguna prohibición constitucional para que esta elección pública fuera tomada, sea en el ejercicio de la democracia directa o en el ejercicio de la democracia representativa. Incluso es esta la esencia de la idea de la efectiva participación popular en el contexto de un Estado social y democrático de Derecho. El ciudadano debe ser entendido como un sujeto de decisión y no de mera prestación de servicios de terceros en sustitución a los agentes estatales.

64 Wunder (2013), p. 136. Traducción libre.

65 D’Oliveira (2003), p. 84. 
No hay ninguna conexión necesaria entre la subsidiariedad y la participación, pese a que la retórica gerencial a buscado en todo mometo dicho encaje. En el caso brasileño, hacer que las decisiones sean tomadas en esferas más próximas del ciudadano no resultan necesariamente en la obtención de decisiones más democráticas o más adecuadas al desarrollo del país de forma civilizada, al revés, pueden suscitar el surgimiento de prejuicios y la defensa de intereses particularizados que no siempre coincidirán con la idea general de supremacía del interés público sobre el privado, como fundamento mayor del Derecho administrativo brasileño. No se discrepa de Jaime Rodríguez-Arana, cuando el autor afirma que, "en el marco de las nuevas políticas, se tiene claro que los ciudadanos, la gente, son los auténticos dueños de la administración pública, y se es consciente de que también la Constitución es el marco para la acción política" ${ }^{66}$ El problema es que no siempre los anhelos populares estarán en conformidad con las disposiciones del sistema constitucional (principalmente en temas sensibles, como la reducción de la mayoridad penal, la pena de muerte, el aborto, la unión de personas de mismo sexo, etc.).

Además, no se debe tener la ilusión de que "la democracia se concluye por la mera disposición de canales de participación por el poder público" ${ }^{67}$ Ampliar la esfera de la sociedad civil no expresa, como aparenta creer el proyecto de reforma gerencial adoptado a partir de los 90 (y aún vigente en la idea de construcción artificial de un tercer sector en Brasil), un rechazo a la actuación del Estado o entenderlo como un organismo accesorio.

Es cierto que, jurídicamente, el Estado tiene un rol primordial en esta tarea cuyo deber es la felicidad y cuyo fundamento es el interés público (y no la subsidiariedad), lo que no inhibe de ninguna manera su obligación de reconocer y garantizar la participación democrática de la sociedad civil, tanto en la esfera política en general como en la administrativa. Dicha participación no debe ser priorizada en la prestación de servicios y sí en las diferentes esferas de decisión y control, incluso relativas al propio sistema federativo y sus distintas instancias de control. En estos términos es que deja de ser posible la aceptación de que el sistema de descentralización administrativa brasileña se guíe por la subsidiariedad, y que tampoco esto podría ser legitimado por un modelo de Estado gerencial-liberal; al

66 Rodríguez-Arana (2011), p. 37.

67 Costa (2002), pp. 167-168. Traducción libre. 
revés, se está de acuerdo con Bercovici que el "Federalismo Cooperativo" típicamente brasileño se relaciona estrictamente con el Estado social intervencionista. ${ }^{68}$

Hay autores que proponen que los municipios constituyen "el nivel de gobierno más apto para comprender las necesidades de sus ciudadanos y para proveer de forma más eficaz y responsable sus carencias"; y en decurso de ello, el reconocimiento del municipio como un ente federativo habría fortalecido el principio de subsidiariedad. ${ }^{69}$ Con todo, esta no parece ser la mejor opción hermenéutica.

El raciocinio que puede ser extraído del mecanismo brasileño de atribución de potestades prevé que las entidades municipales serán responsables de todo lo que pueda ser encuadrado como interés local. Esto desde que no sea un interés previamente reconocido como de encargo de la Unión y de los Estados Miembros. Si es así, pues aunque el municipio pueda, desde el punto de vista práctico, realizar de forma eficiente la actividad, no tendrá atribuciones para ello. Y el caso contrario también es verdadero. Si la actividad es de interés local, no importa si la Unión o el Estado podrían prestarlo de forma más eficiente o, aún, no es relevante si el municipio está prestando la actividad de forma insuficiente o precaria. Lo que no puede es la Unión o el Estado intervenir unilateralmente con el fin de prestar servicios a los individuos amparándose en la precariedad municipal. Como mucho, una situación como esta exigiría la celebración de acuerdos como los previstos en el artículo 241 de la Constitución (cuya característica básica es la bilateralidad), siempre siendo respetada la potestad originaria como el fundamento autonómico de la decisión.

El criterio del legislador brasileño no es de la suficiencia o de la eficiencia para la división de potestades, sino de identificación apriorística y principiológica, a partir de elecciones de carácter político-jurídico y no pragmático-político. José Afonso da Silva denomina el criterio general que regula el reparto de potestades entre las entidades componentes de la federación de "principio de predominancia del interés", en los términos que "a la Unión cabrán todos los temas y cuestiones de predominante interés general, nacional, al paso que a los Estados tocarán los temas y asuntos de predominante interés regional, y a los Municipios competen los asuntos de interés local". División esta que no resuelve los problemas concretos que surgen como consecuencia del criterio adoptado, considerándose que, en el día de hoy, se vuelve "cada vez más problemático discernir qué es interés general

68 Bercovici (2005), p. 90.

69 Y el caso de Silvia F. Torres. Faber (2001), pp. 239-242. Traducción libre. 
o nacional de qué sea interés regional o local" ${ }^{70}$ De todos modos, es relevante que el interés público sea subyacente y no la idea iusnatural de que siempre la entidad menor debe ser prestigiada apriorísticamente. Incluso porque el modelo federativo brasileño tiene como fundamento la cooperación entre las unidades federativas, objetivando el desarrollo nacional equilibrado. Según Gilberto Bercovici, la Constitución Federal de 1988 adopta el "principio de solidaridad funcional" entre las diferentes esferas de potestades administrativas (federal, estatal y municipal), instaurando un equilibrio dinámico con la abolición de la rígida partición de potestades. ${ }^{71}$

El entendimiento recurrente de que la subsidiariedad es el fundamento utilizado siempre que se busca fundamentar la acción conjunta de diversas entidades menores en la solución de problemas comunes (propuesta de autores como Margarida Salema d'Oliveira Martins), ${ }^{72}$ no es verdadero cuando es aplicado en Brasil. Muchas veces la acción de diversas entidades menores requiere justamente el movimiento opuesto al de la subsidiariedad, mediante la creación de entidades a nivel más centralizado (aunque para funciones exclusivamente administrativas).

Ejemplo típico de esta situación en Brasil, como lo ya dicho, son las regiones metropolitanas, que pueden recibir poderes administrativos y recursos financieros destinados a los servicios transferidos como de su potestad (volviéndose, por lo tanto, un nivel administrativo intermedio entre el Estado y municipios, cuyo aspecto estructural será el de una entidad autárquica, paraestatal, consorciada o meramente orgánica -como un consejo o secretaría). ${ }^{73}$ La tendencia futura es de la existencia cada vez mayor de intereses que sobrepasan las fronteras municipales, estatales o nacionales, principalmente respecto al desarrollo humano y ambiental. Dichos intereses, resultantes de la necesidad de ampliada complejidad, difícilmente serán mejor atendidos por medio de recursos locales, lo que vuelve la subsidiariedad un instrumento tendencialmente obsoleto.

No es posible conectar plenamente la subsidiariedad a la descentralización federativa. Y esto es típico del federalismo de doble grado en el que "la potestad

70 Silva (2008), p. 478. Traducción libre.

71 Bercovici (2005), pp. 89-90.

72 D'Oliveira (2003), p. 35.

73 MACEDo (2005), p. 94. 
y la autonomía son irreductibles, excepto si por enmienda constitucional" ${ }^{74} \mathrm{La}$ descentralización política de la Federación brasileña retrata una clara autonomía entre los entes federados, siendo que cada uno tiene sus atribuciones, a no ser que se trate de potestades comunes o concurrentes. Caso en el que también no se aplicará la subsidiariedad, aunque por motivo diverso: todos pueden actuar en conjunto (en las potestades comunes, sin ninguna relación de prioridad) o la Unión podrá aprobar normas generales vinculantes (en el caso de las concurrentes -lo que resultaría en la adopción de un criterio no sólo paralelo, sino contrario del de la subsidiariedad, una vez que la preferencia es del ente mayor en detrimento de los menores). ${ }^{75}$

Las reales dificultades inherentes a la actuación de los municipios como entes federativos eficientes en la realización de las políticas públicas por las que son responsables no está en la división constitucional de potestades; su gran cuestión no es predominantemente jurídica o de descentralización administrativa. Para que los municipios derroten la lógica centralista tradicionalmente existente en Brasil, deben también vencer el difícil (y no raramente inocuo) desafío de reducir su dependencia financiera, como también la ausencia de condiciones materiales bajo las que la mayoría de ellos está sometida (y los propios Estados en general no son excepción de esta situación). ${ }^{76}$

Es común que los gobernantes utilicen el principio de subsidiariedad paradójicamente, como argumento para que su autonomía resulte en una exoneración de los Estados y de la Unión. Hecho este que sólo refuerza la regla de la precariedad de la autonomía municipal (con énfasis en la economía), una vez que "la autonomía de los entes federados ante la Unión puede transformarse en una farsa cuando faltan los recursos necesarios para su mantenimiento" ${ }^{77}$ Al contrario de una visión subsidiaria, es necesario que los Poderes Públicos se vuelvan conscientes y que actúen en el sentido de reconocer lo que desde hace mucho ya constató Regina Maria Macedo Nery Ferrari: "la comunidad local está insertada en un contexto mayor del de la comunidad estatal y federal. Así, las carencias locales se proyectan también en este contexto más amplio, lo que

74 Menezes (2005), p. 113. Traducción libre.

75 Dias (2005), pp. 61 y ss.

76 Barroso (2002), pp. 141-151.

77 Bercovici (2005), p. 91. Traducción libre. 
hace que también haya interés estatal y federal en el buen curso y desarrollo de las entidades locales" ${ }^{78}$

\section{CONClusiones}

La subsidiariedad es un criterio antiguo de definición de potestades en Europa. Por una parte, el criterio refuerza la idea de que el Estado debe responsabilizarse únicamente por lo que la sociedad civil no puede hacer por sí sola; por otro lado, suscribe la descentralización como un principio de reparto de atribuciones políticas y administrativas dentro de los Estados y a nivel de la Unión Europea. Son diversos los documentos jurídicos que tratan sobre el asunto, y es esta la perspectiva dominante respecto del tema.

Ocurre tradicionalmente lo contrario en Brasil. No se habla sobre subsidiariedad, una vez que la idea de descentralización político-administrativa adviene históricamente de la noción de Federación (según el modelo estadounidense). Sin embargo, recientemente la doctrina brasileña empezó a importar la doctrina de Europa en esta esfera; y muy rápidamente se ha vuelto sentido común la aceptación de la subsidiariedad como un criterio constitucional de definición de potestades federativas en Brasil. Es decir, se ha vuelto frecuente el hecho de que juristas brasileños acepten la adopción del criterio de subsidiariedad con el fin de fundamentar la atribución de competencias decisorias (siendo dicha perspectiva también encontrada reiteradamente en la jurisprudencia). El "principio de subsidiariedad" sería la base filosófica que condicionaría la interpretación de la Constitución. La subsidiariedad es una idea presente en tesis no sólo sobre privatización de las actividades públicas, sino también sobre descentralización administrativa en general (ejemplo de esto fue el proyecto de reforma del Estado brasileño en los 90).

Sin embargo, después de analizar las variables constantes en el sistema brasileño, este artículo concluye que esta visión predominante necesita ser revista. Se parte del supuesto que el texto de la Constitución Federal de 1988 excluye expresamente el criterio de subsidiariedad, que estaba en la Constitución anterior, pero que fue derogado debido a una opción deliberada del legislador constituyente. Además, a partir de una interpretación sistemática del texto constitucional brasileño actual, no es posible admitir una interpretación favorable a

78 MACEDO (2003), p. 63. Traducción libre. 
la idea; ni siquiera sería posible considerar la subsidiariedad como un principio constitucional implícito.

En Brasil, el criterio fundamental de atribución de potestades es el del interés público predominante. Es decir, a veces la Constitución prestigia los Estados, otras la Unión, y otras los municipios. El tema "servicios públicos" es un buen ejemplo de esta realidad, en el que las potestades son conferidas a los entes federados por medio de un criterio pragmático (de eficiencia). En esta temática la Unión conserva las principales potestades, y la potestad residual es de los estados miembros de la Federación (no de los municipios). Los gobiernos locales tuvieron un aumento de su poder y de sus responsabilidades a partir de 1988 (fueron, incluso, transformados en "entes federativos"), aunque esto no significa que la Constitución brasileña atribuya alguna regla de preferencia para su actuación (y en realidad es al revés).

En resumen, se puede decir que no siempre la importación de tesis doctrinales extranjeras es la mejor forma de comprender la realidad nacional. Parece razonable defender que cada vez más es necesario reforzar las nociones contemporáneas de solidaridad y de responsabilidad compartida como un fundamento de la organización político-administrativa brasileña; y parece ser justamente esto lo que la Constitución Federal de 1988 hace (aunque no lo disponga expresamente; y aunque este sea un modelo con muchos problemas).

En Brasil, el poder que tiene la Unión Federal es muy grande. No sería un equívoco afirmar que se trata de un país formalmente federado, aunque materialmente unitario. Por lo tanto, diferentemente de Europa (o incluso de los Estados Unidos), no tiene sentido pensar en la subsidiariedad como un criterio hermenéutico dentro del sistema jurídico brasileño. E incluso en Europa el contexto de integración supranacional vivido demuestra que muchas veces el criterio formal de subsidiariedad no fue aplicado cuando el mayor objetivo fue el de ampliar la integración regional o fomentar el desarrollo. En la práctica, el tema de la centralización y descentralización de potestades es un problema mucho más complejo que cualquier otro criterio apriorístico adoptado como solución general.

\section{REFERENCIAS Bibliográficas}

Albanese, Alessandra (2002): "Il principio di sussidiarietà orizzontale: autonomia sociale e compiti pubblici”, en Rivista Diritto Pubblico. (Año 1, No 1, jan./ abr.), pp. 75-85.

Bacellar Filho, Romeu Felipe (2009): Reflexões sobre Direito Administrativo. (Belo Horizonte, Fórum). 
Barroso, Luis Roberto (2002): "A derrota da federação: o colapso financeiro dos estados e municípios", en Temas de Direito Constitucional (Río de Janeiro, Editorial Renovar).

BAZÁN, Víctor (2013): "El federalismo argentino: situación actual, cuestiones conflictivas y perspectivas", en Estudios Constitucionales (Año 11, No 1), pp. 37-88.

BerCovici, Gilberto (2005): Constituição econômica e desenvolvimento: uma leitura a partir da Constituição de 1988 (São Paulo, Malheiros).

Bercovici, Gilberto (2014): "Revolution trough Constitution: the Brazilian's directive Constitution debate", en Revista de Investigaçôes Constitucionais (Vol. 1, No 1, jan./abr.), pp. 7-18.

BRASIL (1982): Programa Nacional de Desburocratização (Brasília, Editorial de la Secretaria de Modernização e Reforma Administrativa).

BRASIL (1995): Plano Diretor da Reforma do Aparelho do Estado (Brasília, Editorial de la Presidência da República).

Bresser Pereira, Luiz Carlos (1996): Crise econômica e reforma do Estado no Brasil: para uma nova interpretação da América Latina (Traducc. Ricardo Ribeiro e Martha Jalkauska (São Paulo, Editorial 34).

Bresser Pereira, Luiz Carlos (1998): Reforma do Estado para a cidadania: a reforma gerencial brasileira na perspectiva internacional (São Paulo, Editorial 34).

Brunet Estarrelas, Pere J.; Almeida García, Fernando; Coll López, Miquel (2005): "Agenda 21: subsidiariedad y cooperación a favor del desarrollo territorial sostenible", en Boletín de la A.G.E. (Año 2005, No 39), pp. 423-446.

Cabral de Moncada, Luis (2005): "A subsidiariedade nas relações do Estado com a economia e a revisão constitucional", en Jorge Miranda (Coord.), Estudos em homenagem ao prof. Doutor Joaquim Moreira da Silva Cunha (Lisboa, Editorial de la Faculdade de Direito da Universidade de Lisboa).

Comissão das Comunidades EuropéIAs (2001): “Governança Européia: Um livro branco" [fecha de consulta: 13 de mayo de 2013]. [Disponible en: http:// eur-lex.europa.eu/LexUriServ/site/pt/com/2001/com2001_0428pt01.pdf].

Costa Ricardo Schier, Adriana da (2002): A participação popular na Administração Pública: o direito de reclamação (Río de Janeiro, Renovar).

D'Oliveira Martins, Margarida Salema (2003): O princípio da subsidiariedade em perspectiva jurídico-politica (Coimbra, Coimbra).

Dias Menezes de Almeida, Fernanda (2005): Competências na Constituição de 1988 (São Paulo, Atlas). 
Faber Torres, Silvia (2001): O princípio da subsidiariedade no Direito Público contemporâneo (Río de Janeiro, Renovar).

Figueiredo, Marcelo (2008): "La evolución politico-constitucional de Brasil”, en Estudios Constitucionales (Año 6, No 2), pp. 209-246.

Gabardo, Emerson (2002): Princípio constitucional da eficiência administrativa (São Paulo, Dialética).

Gabardo, Emerson (2003): Eficiência e legitimidade do Estado (São Paulo, Manole).

Gabardo, Emerson (2009): Interesse Público e subsidiariedade (Belo Horizonte, Fórum).

Gesta Leal, Rogério (2003): Direito Urbanistico: condiçôes e possibilidades da Constituição do Espaço Urbano (Río de Janeiro, Renovar).

GraU, Eros Roberto (2002): A ordem econômica na Constituição de 1988 (São Paulo, Malheiros).

GuALDANI, Annalisa (2007): I servizi sociali tra universalismo e seletività (Milano, Giufrè).

Justino de Oliveira, Gustavo Henrique (2005): "A arbitragem e as parcerias público-privadas”, en Carlos Ari Sundfeld (Coord.), Parcerias público-privadas (São Paulo, Malheiros).

Justino de Oliveira, Gustavo Henrique (2008): Contrato de gestão (São Paulo, RT). Lopez Pintor, Rafael (1993): “¿Es la sociedad española solidaria?”, en Juan María Laboa (Dir.), Solidariedad y subsidiariedade en la sociedade española (Madrid, Universidade Pontifícia Comilas de Madrid).

Macedo Nery Ferrari, Regina (2003): Controle da constitucionalidade das leis municipais (São Paulo, RT).

Macedo Nery Ferrari, Regina (2005): Direito Municipal (São Paulo, RT).

Machado HorTa, Raul (1995): "Direito constitucional brasileiro e as regiōes metropolitanas", en Estudos de Direito Constitucional (Belo Horizonte, Del Rey).

Marzuoli, Carlo (2005): "Sussidiarietà e libertà", en Rivista di Diritto Privato. (Año 25, No 1), pp. 5-31.

MoreIra, Vital (1997): Administração autônoma e associações públicas. (Coimbra, Coimbra).

MоттA, Fabrício (2007): Função normativa da Administração Pública (Belo Horizonte, Fórum).

Musetti Grotti, Dinorá Adelaide (2003): O serviço público e a Constituição Brasileira de 1988 (São Paulo, Malheiros). 
NeF, Jorge (2010): "Administração pública e reforma do setor público na América Latina”, en Guy Peters e Jon Pierre (Orgs.), Administração pública: coletânea. Traducc. Sonia Midori Yamamoto e Mirian Oliveira, (São Paulo, UNESP).

Nogueira AlcalÁ, Humberto (2008): "La evolución político-constitucional de Chile 1976-2005", en Estudios Constitucionales (Año 6, No 2), pp. 325-370.

Nunes Ferreira, Gabriela (1999): Centralização e descentralização no império (São Paulo, Editorial 34).

ONU (2008): "Conferência das Nações Unidas sobre Meio Ambiente e Desenvolvimento (CNUMAD)" [fecha de consulta: 8 de novembro de 2008] [Disponível em: http://www.ecolnews.com.br/agenda21/index.htm.]

Pinto e NetTo, Luísa Cristina (2005): A contratualização da função pública (Belo Horizonte, Del Rey).

PirEs, Francisco Lucas (1994): "O Comitê das Regiões e subsidiariedade no Tratado de Maastricht", en Conferência Luso-Alemã: as experiências constitucionais face a uma Europa Unida (Lisboa: Fundação Konrad Adenauer).

Pironti Aguirre de Castro, Rodrigo (2007): Sistema de controle interno: uma perspectiva do modelo de gestão pública gerencial (Belo Horizonte, Fórum).

Ramos, Naidar et al (1980): Modernização Administrativa: coletânea de monografias II (Brasília, IPEA).

Rivero, Oswaldo (2002): O mito do desenvolvimento: os países inviáveis no século XXI (Traducc Ricardo A. Rosenbusch, Petrópolis, Vozes).

Rodríguez-Arana MuÑoz, Jaime (2006): El buen gobierno y la buena administración de instituciones públicas (Navarra, Aranzadi).

RodríGUez-Arana, Jaime (2011): Reforma administrativa y nuevas políticas públicas (México, Liber Iuris Novum).

SAnZ Larruga, Francisco Javier (1999): "El concepto de responsabilidad compartida y el principio de subsidiariedad en el derecho ambiental", en Anuário da Faculdade de Dereito da Universidade da Coruña, (Año 1999, № 3), pp. 559-582.

SiLva, José Afonso da (2008): Curso de Direito Constitucional Positivo (São Paulo, Malheiros).

Sousa Wahrlich, Beatriz M. De (1974): "Reforma administrativa federal brasileira: passado e presente", en Revista de Administração Pública (Año 8, abr./ jun), pp. 27-75. 
StUART, Ana Maria (2002): "Regionalismo e democracia: o papel do Comitê das Regiōes na Uniāo Européia”, en Anais. $3^{\circ}$ Encontro Nacional da ABCPAssociação Brasileira de Ciência Política (Niterói, 28-31 jul.).

Sundfeld, Carlos Ari (2002): Fundamentos de Direito Público (São Paulo, Malheiros).

Wahrlich, Beatriz (1984): "A reforma administrativa no Brasil: experiência anterior, situação atual e perspectivas - uma apreciação geral", en Revista de Administração Pública (Año 18, jan./mar., No 1), pp. $49-59$.

Wunder Hachem, Daniel (2011): Princípio constitucional da supremacia do interesse publico (Belo Horizonte, Fórum).

Wunder Hachem, Daniel (2013): "A noção constitucional de desenvolvimento para além do viés econômico: reflexos sobre algumas tendências do Direito publico brasileiro", en $A \& C$ - Revista de Direito Administrativo \& Constitucional (Año 13, No 53), pp. 133-168.

Wunder Hachem, Daniel (2014): "Derechos fundamentales económicos y sociales y la responsabilidad del Estado por omisión”, en Estudios Constitucionales (Año 12, No 1), pp. 285-328.

Zanella di Pietro, Maria Sylvia (2002): Parcerias na Administração Pública: concessão, permissão, franquia, terceirização e outras formas (São Paulo, Atlas). 